\title{
Reflexiones ante el sínodo extraordinario
}

\section{CARIOS RAFAEL TURCIOS Centro de Reflexión Teológica. San Salvador.}

El 25 de enero de este año, 26 años después de que Juan XXIII anun. ciara el Vaticanc II y en el mismo lu. gar, la basílica de San Pablo, Juan Pablo Il ha anunciado un sinodo extraordinario de obispos para fines de este año. Este anuncio ha sorprendido por lo inesperado, pero sobre todo por la incertidumbre sobre su significado. ¿Se trata de una confirmación del concilio Vaticano II o de una evaluación? Y si es esto último, ¿se trata de corregir los errores en su aplicaciōn y de bendecir sus innumerables frutos positivos, todo ello con honr. dez y sin prejuicios? ¿Se trata de frenar al concilio o de impulsarlo hacia adelante? Estas son las preguntas que suscita el anuncio del sinodo para las cuales no hay lodavia respuestas claras. Más allá de afirmaciones generales apaciguadoras existe, sin embargo, el temor de que el sinodo se oriente más a frenar que a impulsar el concilio. Las pesimistas declaraciones del cardenal Ratzinger a la revista italiana Gesù, publicadas ahora en forma de libro, sobre la urgente necesidad de una restauración en la Iglesia más parecen augurar to primero que lo segundo. Pero, de nuevo, ¿son estas declaraciones la opinión personal del cardenal Ratzinger, aunque no hay que olvidar que es el prefecto de la hoy muy influyente congregación para la doctrina de la fe, o responden a una opinión más generalizada en el Vaticano? ¿No apuntan en esa dirección también algunas palabras de! Pa. pa en su reciente viaje a Holanda, Bélgica y Luxemburgo?

La incertidumbre proviene también del balance general de los siete años del pontificado de Juan Pablo II, quien indudablemente imprimirá un sello propio al sinodo. En los aspectos más externos es indudable que el Papa actual es popular como pocos pontifices lo han sido, y asi lo atestiguan sus numerosos viajes. Por otra parte, esos mismos viajes provocan controversias, como las ocurridas püblicamente en Estados Unidos, en Nicaragua y ahora en Holanda y Bélgica y exigen grandes dispositivos de seguridad para prevenir atentados, cosa nunca vista hasta ahora. Más de fondo, Juan Pablo li se muestra sensible a los problemas de la justicia y 
de los pobres, mientras se mantiene intransigente frente a temas de doctrina y de disciplina eclesiástica (celıbato, moral sexual, acceso de la mujer a los ministerios, amonestaciones a teó. logos europeos y latinuamericanos. advertencias criticas a la teología de la liberación, suspensiōn de los sacerdo. tes ministros en el gobierno sandir.is. ta, etc). Favorece y propicia movl. mientos de renovación apostólica y espiritual (Opus Dei, Focolarmi, nes. catecumenales, Comunıón y Libera. ciōn, etc.) de corte claramente espiritualista y tradicional, mientras que ha hecho serias advertencias a órdenes religiosas seculares (jesuitas, francisca. nos, carmelitas) que han intentado en serio una renovación, audaz en algunos puntos, pero fieles a la inspiración del concilio y de Medellín para América Latina. El movimiento ecuménico, por otro lado, se encuentra es. tancado y frenado, mientras que el movimiento litürgico ofrece sintomas de retroceso, como lo mostraría la promoción de la misa en latín según el rito de Pio $V$

En este contexto eclesial hay que preguntarse por el significado del próximo sínodo. En principio, la respuesta está abierta y mucho dependeră del trabajo previo en el cual las iglesias locales evalüen con honradez los últimos veinte años y ofrezcan esa realidad al sinodo. Pero tampoco se puede ignorar que los hechos men. cionados más han causado hasta aho. ra temor que esperanza entre quienes ven en el concilio una realidad sumamente positiva para la Iglesia y para el mundo, al cual, por lo tanto, más que frenarlo hay que potenciarlo, aunque se corrijan también los errores que se hayan podido cometer en su nombre.

Como ayuda para comprender lo que puede suceder en el próxımo sinodo ofrecemos un breve análisis de los acontecimientos eclesiales en los últimos veinte años y la particıpación de Juan Pabio ll en ellos.

\section{El significado fundamental del Vaticano II}

E! concilio convocado por Juan XXIII en 1959 llegó con un relraso de sıglos. La Iglesia tuvo que comenzar a aggiornarse después de cidatro siglos de inmovilismo y de rechazo a la modernidad. El Vaticano II dialogó con los movimientos nacidos de la edad moderna: la reforma, la ilustra. ción, la revolución francesa. Hasta el concilio la Iglesia habia adoptado una postura francamente negativa hacia la modernidad (cfr. el Syllabus de Pio IX), no tanto por los peligros de ponerse en connivencia con la burguesia que la propiciaba, sino por el miedo a perder sus privilegios tradicionales de la época de cristiandad medieval. En el concilio la Iglesia comenzó a dialogar con esos movimientos que hasta entonces habia rehuido y anatematizado, como lo muestran claramente sus documentos sobre ecumenismo, libertad religiosa, la misión de la lglesia en el mundo, etc.

Muy bien estuvo ese diálogo, pero hay que recordar que el retraso se paga caro, y eso hay qe tenerlo tam. bién en cuenta al lamentarse de ciertas exageraciones postconciliares. EI Vaticano II fue un deshielo y el deshielo puede producir innundaciones, fue un instroducirse en terreno desconocido $y$ eso produce tambiên sobresaltos y problemas. El excesivo entusiasmo frente al mundo moderno y su progreso, el poco sentido critico hacia la modernidad que 
han originado males postconciliares no hay que achacarlos, por lo tanto, a la intuición novedosa y cristıana del concilio, sino al retraso con que se produjo. $Y$ junto al desfase temporal, está también el geográfico. Los princi. pales protagonistas teológicos y episcopales del concilio fueron centroeuropeos. Ni los paises de Europa meridional y oriental, nı los paises del tercer mundo jugaron un papel relevante en el concilio. De esta manera no pudo tomar forma el anhelo de Juan XXIII de proclamar una Iglesia de los pobres y una visión más popular de la le y de la Iglesia.

Estos desfases, histöricamente inevitables, pueden explicar algunas de las exageraciones postconciliares; pero nada quitan de validez a sus in. tuiciones fundamentales sobre la relación de la Iglesia con el mundo. La his. toria posterior ha mostrado cómo se puede lograr un diálogo más crítico y maduro con la modernidad $y$, sobre todo, cómo la lógica más profunda del concilio permite y propicia una Iglesia de los pobres.

En este contexto y problemática de fondo hay que estudiar las aportaciones del entonces obispo Karol Wojtila, pues ilustran su apreciación global del fenómeno conciliar su problemática y su visión de la lglesia en el mundo. Sus intervenciones conciliares a partir de las Actas Concihares han sido recientemente publica. das (véase M. Alcalá, "Karol Wojtyla y el Vaticano II," Razón y Fe 1002 (noviembre 1981) pp. 454-471, reproducido en Encuentro, 17. pp. 136-147).

Ya en la primera consulta conciliar el obispo Wojtyla aparece muy interesado en temas doctrinales, denunciando cualquier tipo de materialismo (científico, positivista o dialéctico) $y$ enfatizando la importancia del orden espiritual y transcendental. Positivamente, se adhiere a y propicia una vi. sión personalista de raíz tomista y scheleriana. Pero su principal preocupación aparece centróda en remas pastorales: los seglares y su relación con el clero, la formación del clero y el celibato, la vida religiosa y el contral de la jerarquía sobre ella por medio de un visitador apostólico es. table, elc.

Dentro ya del concilıo, su actuación más importante ocurrió en la discusión del Esquema XIII, "La Iglesia y el mundo de iny. "Se convirtó en portavoz del llamado esquema "cra. coviense," más espiritualista, dualista y menos optimista que el presentado por la comisión conciliar. Dicho esquema cracoviense no lue aceptado, sino muy parcialmente por el concilio. Más tarde varias ideas del proyecto cracoviense pasarán a las encíclicas Redemptor Hominls y Dives in mise. ricordla.

Como resumen de las aportaciones de Mons. Wojtyla al Vaticano II puede decirse que en ellas se refieja una preparación concienzuda y sólida, un claro sentido de colegialidad con los obispos polacos, una gran trabazón filosófica, marcada por un personalismo ético, en un estilo profesoral y académico, dentro de una actitud moderada y constante al mismo tiempo. Sus aportaciones muestran una notable apertura a los temas sociales, económicos y políticos en releción con la vida cristiana, con predominio de lo pastoral sobre lo teológico, una profunda actitud religiosa dentro de una espiritualidad de transcendencia con una clara reserva ante el optimismo de las corrientes seculares y las metodologias inductivas con 
acento sociológico. Insisten en el carácter sobrenatural de la misión salvífica de la Iglesia, en el valor central de la cruz y en la esperanza hacia el futuro del reino. Muestran preocupación por los temas éticos y de moral católica, por la cultura y la necesidad de que ésta sea sacralizada por la Iglesia, por la formación del cle. ro dentro de una visión eminentemente sacral del sacerdocio, por la subordinación de los aspectos proféticos y carismáticos de la vida religiosa a una pastoral de conjunto con acentuación del centralismo jerárquico y por la insistencia en la relación fraterna entre clero y laicado, aunque siempre éste ültimo subordinado a aquél.

También aparece en sus aportaciones una tendencia no disimulada a ofrecer la experiencia de la lglesia polaca como punto de contraste y rectificación a las tendencias de la Europa occidental que aparecían en el aula conciliar. La Iglesia polaca, por su situación dentro de los paises del este europeo, se vio sorprendida por muchos planteamientos conciliares que respondian a un mundo cultural, social, político y teológico muy diverso. Observaba en ello un optimismo demasiado fácil, un riesgo de desintegración eclesial y de pérdida de identidad. Ante esto se ofrecia la imagen de la iglesia polaca, del nacionalcatolicismo polaco, sin fisuras internas y sin ninguna concesión al maxismo, como lo muestra el fuerte ataque de los obispos al movimiento Pax de cristianos polacos por el socialismo.

\section{La recepción del Vaticano II}

Todo concilio necesita un periodo de "recepción" más o menos largo. Suelen ser épocas de conflictos y tensiones, como han estudiado historiadores de la Iglesia y eclesiōiogos como Y. Congar y A. Grillmayer. El Va. ticano Il tan poco fue una excepción.

Tras los primeros años de entusiasmo y fervor, pronto aparecieron las polarizaciones en las iglesias. Por poner dos ejemplos simbólicos. mientras la enciclica Humanae Vitae suscitó reacciones negativas en amplios sectores eclesiásticos los cuales vieron en la encíclica un rompimiento con el espíritu del concilio. Mons. Lefevbre capitaneó una vuelta a Trento acusando al Vaticano II de protestante y comunista. Es conocido que los últimos años de Pablo VI estuvieron marcados por el sufrimiento $y$ las dudas ante esas tensiones eclesiales postconciliares.

En general se puede decir que mientras en el primer mundo, Europa y América del Norte, la Iglesia avanza. ba en la línea de la modernidad secular, en el tercer mundo y especialmen. te en América Latina tomaba otros derroteros: el camino de la justicia y la solidaridad con los pobres (Medellin y Puebla). En los países del este europeo, y en concreto en Polonia, los documentos del Vaticano II fueron recibidos de forma peculiar, en parte por las dificultades políticas de su publicación y en parte por la configuración del nacional-catolicismo polaco. En este contexto hay que leer las intervenciones del ya cardenal Wojtyla en los sínodos de Roma que refiejan el postconcilio de la Iglesia polaca (véase M. Alcalá "Karol Wojtyla y el Sinodo Romano," Estudios Ecleslésticos, junio 1982, reproducido en Encuentro, 17, pp. 144-153).

Ningūn obispo polaco pudo asistir al primer sínodo celebrado en Ro- 
ma en 1967. El gobierno polaco negó al cardenal Wyszynski el pasaporte para viajar a Roma y, como respuesta, los otros obispos polacos elegidos para el sínodo $-y$ entre ellos el ya cardenal Wojtyla - se negaron a asistir en solidaridad con el primado polaco. La tensión entre la Iglesia y el gobierno polaco se agudizó en 1966, año en el que la Iglesia polaca celebraba el milenario del bautismo del principe Mieszko, origen del nacionalcatolicismo polaco. El gobierno habia negado la entrada a Polonia de Pablo $\mathrm{VI}$, especialmente invitado para la celebración del milenario, y puso dificultades para la publicación de los documentos conciliares "por falta de papel." Hasta 1967 se pudieron publicar los documentos conciliares en Polonia.

El cardenal Wojtyla asistió y tuvo un papel importante en los siguientes sinodos: en el de 1969 sobre las rela. ciones entre las conferencias episcopales y la Santa Sede, en el de 1971 sobre sacerdocio y justicia, en el de 1974 sobre evangelización y en el de 1977 sobre catequesis. Esta presencia del cardenal Wojtyla en los sínodos configuró definitivamente su personalidad eclesial y lo dio a conocer al episcopado de la Iglesia universal $\mathrm{Co}$ mo hombre de fe, de arrolladora personalidad, seguro en la doctrina, hábil en el diālogo y fácil poliglota.

El análisis del conjunto de sus intervenciones permite estas conclusiones. El cardenal Wojtyla posee un cuerpo doctrinal sólido, de estilo tradicional escolástico-tomista, con predominio filosófico personalista, predilección por una metodología teológica de carácter deductivo, con menor valoración del método inductivo a partir de la experiencia vital de la fe.
En sus intervenciones se notan reser. vas hacia los anălisis sociológicos y los aportes de las teologias europeas y latinoamericanas postconciliares. Su concepción biblica es tradicional y más como apoyo al dogma que como punto de partida para la reflexión teo. lógica. Se preocupa por las relaciones entre teologia y magisterio, insistiendo en la subordinación directa de la reologia al servicio de la fe y del magisterio. Concibe a la Iglesia como sacramento sobrenatural de salvación y subordina a este aspecto las restantes perspectivas eclesiales. Apoya la doctrina y la práctica de ia colegialidad episcopal, reflejada en el sinodo consultivo, y se nota despreocupación hacia las cuestiones más teóricas que suscita el tema de la colegiabilidad. Se interesa por la problemática sacerdotal (vida espiritual, vida interior, formaciōn) y concibe el ministe. rio de forma predominantemente sa. cral, apoya el celibato y muestra reservas ante la posibilidad de ordenar a varones casados. Acentúa enérgicamente la actuación sacramental del sacerdocio y muestra reservas hacia las actuaciones socio-politicas de los sacerdotes. Tiende a subordinar la exención de las órdenes religiosas a la pastoral de conjunto. Se interesa en potenciar la actividad del seglar en la Iglesia, subordinada siempre a la jerarquia, y desconfía de las comunidades de base.

Sus intervenciones sinodales traslucen una concepción de evangelización como tarea de indole sobrenatural, insistiendo clara y explicitamente en su carácter salvifico y en la cruz. El desarrollo humano es concebido dentro de un escala vertical de valores, subordinando la promoción socioeconómica a la espiritual, y 
todo ello dentro de un dinamismo sacrailizador. La liberación es centrada sobre todo en los derechos de la persona, presuponiendo siempre la liberación del pecado personal y colectivo. Se hace presente un antimarxismo visceral, fruto de su experiencia pola. $c a, y$ una descofianza ante cualquier análisis, incluso latente, que estuviera basado en el materialismo histórico por considerarlo inseparable del ma. terialismo dialéctico y del ateismo. El proceso de secularización es visto con reservas por su peligro de llevar al secularismo y por los resultados negativos de las formas occidentales de la secularización. Aparece finalmente la convicciōn de que la Iglesia polaca ha llevado a cabo el postconcilio de forma ejemplar y de ahi la tendencia a ofrecerla como modelo para la Iglesia universal.

\section{El modelo eclesial de Juan Pablo II}

La experiencia polaca, la cual tan profundamente ha marcado al obispo Wojtyla, parece ofrecer a Juan Pablo II un modelo eclesial aplicable a la Iglesia universal. La Iglesia polaca ha vivido más de mil años de un catolicismo nacional que ha sido su principal fuente de identidad nacional y de cohesión cristiana. Frente al comunismo, ha ofrecido la imagen de una fortaleza sin fisuras, una especie de acles ordinata que ha resultado eficaz para la defensa de los derechos humanos, la libertad religiosa y el respeto a las tradiciones del pueblo. Esta Iglesia valora sobre todo la unidad y por ello no es nada extraño que movimientos, como el ya citado Pax, hayan sido duramente criticados por la jerarquía por considerarlo atentatorio de la unidad.
No es nada exagerado decir que este modelo de la iglesia polaca tiene mucho de cristiandad, lo cual expli. caría la reticencia de los obispos polacos ante el Vaticano II en aquellos puntos que implican un nuevo mode. to eclesial postmedieval y moderno. Pero ofrece la ventaja, por otra parte, de mostrar a una Iglesia eficaz y con impacto social en el mundo. ¿Es aventurado pensar que este modelo pola. co se quiera extender ahora a la Igle. sia universal con los retoques y las adaptaciones necesarias? Según algunos, precisamente para que la Iglesia pueda presentarse y hacer frente al mundo de hoy, un mundo de injusticia, de opresión, de amenazas nucleares, necesitaria ante todo aparecer como una comunidad disciplinada, compacta, unida y fuerte. Frente a la crisis ideológica y a las tensiones esteoeste, la Iglesia podría ofrecer al mundo su doctrina social, sus valores morales y religiosos en orden a construir la civilización del amor; y no se puede desconocer que, dado el vacio moral del mundo moderno, muchos sectores eclesiales han recibido con entusiasmo esta alternativa eclesial. La Iglesia ofrecería al mundo las respuestas a los problemas que las ideologías sociales y políticas son incapaces de dar. Una nueva cristiandad emergería en el horizonte, enraizada en la vieja cristiandad medieval que configuró la cultura occidental europea. La Iglesia se prepararia asi para el año 2.000 . el segundo milenio del cristianismo, del cual Juan Pablo II habla con fre. cuencia.

¿Es esta la concepción de Iglesia de Juan Pablo II? P. Valadier ("Jean Paul II: une vision de l'homme d'après les discours prononcés en France." Etudes 353 (1980) 527-541, resumi- 
do en "Juan Pablo Il: una visión del hombre," Selecciones de Teologia 82 (1982) 107-117) ha estudiado los discursos del Papa en Francia desde su visión atropológica, como oferta a las sociedades desarrolladas y secularizadas de occidente para que vuelvan a reencontrarse. En esos discursos aparecería la antropología necesa. ria para superar la crisis de occidente y la base también para una Iglesia de cristiandad.

Afirma el Papa, según Valadier, que el hombre sölo tiene sentido como imagen y semejanza a Dios y que sólo Dios garantiza al hombre su pro. pia humanidad. La libertad, fraternidad e igualdad, lanzadas por la revolución francesa, tienen raices cristianas. Sólo el evangelio tiene capacidad de solucionar los problemas de hoy. La fe sola, sin necesidad de otros aportes exteriores, es el criterio de discernimiento de las realidades humanas. Juan Pablo II privilegia el nacimiento sobre el devenir, la maternidad sobre la paternidad, más en concreto, la nación como tierra materna sobre el estado paternal, la dimensión de la familia como hogar más que la del dominio de la tierra. Acentúa más la dimensión originaria de la ima. gen de Dios en el hombre que la dinámica hacia la semejanza, más el origen que la escatología, más el arjé que el télos, más la salvación como fidelidad al pasado que como lensión hacia el fin, măs la historia de salvación como realización interior del hombre que como desarrolio histórico en la humanidad.

Estos son los valores que Juan Pablo Il estaria ofreciendo a la vieja Europa para su salvación, valores que una Iglesia de cristiandad puede propiciar, superando la desintegración de dichos valores no frenada por una Iglesia más moderna.

Pero es muy posible que Juan Pablo Il vea la posibilidad de la nueva cristiandad mãs en América Latina que en la Europa ya muy seculariza. da. América Latina aparece todavía como un continente cristiano y poco secularizado. Esto explicaría su preocupación por visitarla, alentarla, preparar cuidadosamente la celebración de los cuatrocientos años de su evangelización, orientándolo todo ello en la dirección de una Iglesia de cristiandad. De hecho sus consejeros para América Latina (el cardenal López Trujillo, Klopenburg, etc.) se sitúan en esta linea, asi como los recientes nombramientos de cardenales (Obando, Lara, Simonis). Junto a esto, las críticas a la teología de la liberaciōn, a los sacerdotes en el gobierno nicaragüense, a corrientes de vida religiosa comprometida con el pueblo, que serian la continuación a las criticas al movimiento polaco Pax. No es que Juan Pablo II no esté interesado en la justicia y en la acción de los pobres, sobre lo cual ha tenido claras y valientes declaraciones; pero desea que la actividad social de la Iglesia se haga desde una Iglesia de cristiandad. Así se explicaria el diferente tratamiento al movimiento de Solidaridad en Polonia y a los movimientos de liberación, incluidos los cristianos, en América Latina.

\section{La evaluación del Vaticano II en el sinodo}

Si lo dicho hasta aquī es correcto, entonces, se abren dos perspectivas fundamentales para evaluar al Vatica. no $l l$ en el futuro sínodo de obispos desde las cuales se intentarán promover dos diferentes modelos de Iglesia. 
Por una parte, se podrán recalcar las exageraciones y desviaciones postconciliares en Europa, en América del Norte y en América Latina y se ofrecería como alternativa el modelo de polaco descrito, válido para toda la Iglesia. Se intentaría volver a una nueva cristiandad - recuérdese que en algunos ambientes se hábla ya del Papa como "lider de occidente" (cfr. la revista Time)- en la cual el cristianismo ofrecería una alternativa pro. pia entre el capitalismo y el comunismo, una respuesta que no sólo recogería la legitima y beneficiosa inspiraciōn evangélica para el mundo, sino que presentaría una solución concreta cristiana, un proyecto sociopolítico, económico e incluso cultural derivado del evangelio y que llevaría a "la civilización del amor," a "la sociedad cristiana," a "la utopia cristiana."

Pero este proyecto es peligroso no sōlo históricamente, como lo muestra el fracaso de tal tentativa, sino desde un punto de vista teológico. Supone, en efecto, una grave confusión entre fe e ideologías, entre evangelio y mediaciones, entre Iglesia y reino. La Iglesia en lugar de discernir en la historia los signos de los tiempos suscitados por el Espíritu para humanizar la historia hacia el reino, se replegaría defensivamente en sí misma; en lugar de ser una avanzada de la humanidad, se convertiria en refugio del status quo, más en concreto, en defensora del neo-conservadurismo político; en lugar de dialogar con las corrientes autónomas de este mundo (sociologia, economia, filosofía, humanismo, etc.) haría del cristianismo la panacea universal, como si desde el evangelio se pudiesen solucionar los problemas del mundo sin necesidad de mediaciones concretas.

Este proyecto conduce, sin duda, a un reforzamiento del poder social y político de la Iglesia -véase la mediaciōn eclesial en conflictos políticos como el del canal de Beagle, cosa que no ocurría desde hace tiempo-, pero también a un peligroso acercamiento de la autoridad eclesiástica al autorita. rismo político de iipo conservador, como el de Reagan. Lleva a adoptar una política de derecinas, preocupada por el orden, la autorioiad, el dogma y la tradición, y la lleva al centralismo eclesiástico, rechazando las iniciativas nuevas que provienen de la base. Lo que todo esto supone en el fondo es una desconfianza hacia el hombre $y$ una sacralización de todas las instituciones por medio de la fe. La ünica re. forma que se contemplaría es la vuelta a la ortodoxia y a la moral, volver a las raíces cristianas, sī, pero entendidas de forma ahistörica, sin perspectivas de futuro.

No se trata en este proyecto simplemente de una involución eclesial, como han manifestado ya muchos, entre ellos también obispos, sino de un peligroso acercamiento al integrismo, tal como la Iglesia lo vivió en épocas pasadas $y$, en este siglo, bajo el pontificado de san Pio X. Si se lee la documentación sobre el movimiento secreto inquisitorial antimo. dernista llamado "La Sapinière" (cfr. J.I. Gonzălez Faus, Memoria de Jesús, memoria de la Iglesia Santander, 1984, 155-197) o las definiciones de integrismo dadas por Blondel (Annales de Philosophie Chrétienne, 1910), por Y. Congar (Falsas y verdaderas reformas de la Iglesia, Madrid, 1953, pp. 451-460) o por el mismo Hans Urs von Balthasar ("Integrisme," Wort und Wahrhelt, 12 
(1963), pp. 737-744, traducidas en Sal Terrae, marzo y julio-agosto (1983 pp. 235-239 y 575.580) se puede constatar que el proyecto de nueva cristiandad no es sólo involutivo, sino que tiene raices integristas: fe esencialista y ahistórica, dualismo naturaleza-gracia, sacralizaciōn del poder y autoritarismo eclesiästico, psicosis de 'estado de sitio,' mentalidad de compelle intrare, poco respeto a la autonomia legitima de las realıdades terrenas, negación práctica de los signos de los tiempos y de la actuación de Dios en la historia, clericalismo, derechización política, subordinación de todo al poder eclesiástico, control doctrinal y moral, poca libertad para los carismas, mantenimiento del orden $y$ de la unidad des. de arriba con medidas coercitivas si es necesario, condena de todo lo que signifique búsqueda o problematiza. ciōn, desconfianza radical hacia nuevas expresiones, etc.; se ha llegado a afirmar incluso una transposición eclesial de la doctrina de la seguridad nacional en una doctrina de la seguridad eclesial.

Si el próximo sinodo discurriese por estas sendas estariamos ciertamente en las antipodas del Vaticano II $y$ del discurso programático de Juan XXill en su inauguración en 1962; sería la tumba del concilio aunque se usasen sus mismas palabras. Pero cabe otra evaluación del concilio $y$ otra propuesta de Iglesia. Para ello es esencial recordar lo fundamental que dijo el Vaticano II -sin ignorar exageraciones $y$ desviaciones - y mantenerlo como la mejor forma para la Iglesia de cumplir con su misiōn en el próximo milenio que se acerca.

Hay que recordar el espíritu del concilio, paradigmáticamente ejem. plificado en el discurso inaugural de Juan XXIII el 11 de octubre de 1962. Dijo entonces el Papa que frente a los profetas de calamidades él prefería ver la acción de la providencia en los acontecimientos históricos del presente: frente a los que deseaban que el concilio se limitase a repetir la doctrina del pasado, él deseaba que la Iglesia diese un paso adelante en la profundización de la doctrina y en el modo de expresarla al mundo actual; frente a los que hubieran deseado condenas dogmáticas, él prefería usar la medicina de la misericordia desde una perspectiva pastoral. Deseaba presentar la Iglesia ante el mundo no como señora, sino como pobre y servidora sin más riqueza que la palabra de Dios. Pablo VI, en la alocución de clausura del 7 de diciembre de 1965, resumió la espiritualidad del concilio como la del buen samaritano.

Buena parte de ese espíritu se hizo presente en el Vaticano ll y sus documentos. Asi, la Iglesia aparece ordenada al reino de Dios, al cual debe convertirse, al cual debe anunciar $y$ realizar. Es una Iglesia, por lo tanto, descentrada de si misma (LG 1,9, etc.) para ser para los demás, en especial para los pobres y sufrientes (LG 8 , GS 1). El ideal de Juan XXIII de una Iglesia de los pobres, sólo esbozado por el concilio, fue recogido y asumido por Medellín y Puebla como concentración significativa y necesaria de una Iglesia conciliar, servidora del mundo y sacramento de salvación.

La Iglesia del Vaticano II es una Iglesia que cree en la actuación del Espíritu, tanto dentro de ella misma (LG 4) como en el mundo (GS $4,11,447$. Es una Iglesia que pretende ayudar a la humanidad (GS 41-43), pero que se deja ayudar también por 
el mundo (GS 44) y que reconoce que todavía le falta mucho en su madura relación con él. Es una Iglesia que reconoce la legitima autonomia de las realidades temporales (GS 36 ) y que los pastores no pueden dar soluciones concretas a todas las cuestiones temporales, sino que les toca a los laicos cumplir esa tarea como propia (GS 43). Es una Iglesia măs dis. puesta a acompañar al pueblo en su marcha hacia el reino que a conside. rarlo puro sujeto pasivo.

La Iglesia del Vaticano II es una Iglesia de comunión, de libertad y de respeto hacia los varios carismas del pueblo de Dios. Todo intento de centralización y monopolio de la vida de la iglesia por parte de la jerarquia es contrario a la eclesiología del pueblo de Dios (GS II). Debe ser respetada la opinión pública dentro de la Iglesia, siguiendo a Pío XII; debe ser realizada la colegialidad episcopal (LG 22-23) que puede ir más allá de los actuales sinodos meramente consultivos. Hay que propiciar la renovación de la vida religiosa (LG VI, PC), el ecumenismo (UR), la reforma litúrgica (5C), la libertad de investigación teo lógica y científica (GS 36,59).

Estos principios inspiradores de! Vaticano ll son los que deben ser promovidos y aplicados a la actual situación para que la iglesia siga avanzando. Desde un punto de vista más intraeclesial, siguiendo el espíritu del concilio, la lgiesia debe mostrar ma. yor sensibilidad hacia los derechos humanos dentro de la Iglesia, como los reclama para el mundo (cfr. GS, DH): respeto a los derechos de la mujer, al derecho al diálogo, a la legítima defensa del acusado, a la libertad de expresión, etc. La misericordia que se proclama ante el mundo debe tener claras manifestaciones en la Iglesia (sacerdotes que piden dispensa del celibato, divorciados que desean acer. carse a los sacramentos, etc.). Debe revisar tambiên la esencia y funciona. miento de las estructurales eclesiales (cardenales, nunciaturas) de acuerdo a la eclesilogía del concilio y no a las eclesıologías medievales que las orıgınaron. Debería revisar importantes principios como los de la colegialidad episcopal y el de la subsidiariedad, lo cual llevaría a repensar el procedi. miento en el nombramiento de obis. pos, a descentralizar la curia vaticana y a conceder mayor autonomía a las conferencias episcopales y a las igle. sias locales. Debería revisar la imagen pública de la Iglesia, de la jerarquía y del papado, especialmente ante los jóvenes y los pueblos pobres, más sensibles a los valores de la pobreza, de la sencillez, del distanciamiento de todo triuntalismo y poder puramente politico, etc.

Vista la Iglesia hacia afuera, e! sínodo debería evaluar seriamente en todo su significado el surgimiento de una Iglesia de los pobres en América Latina, la novedad radical que supone la opción por los pobres. La solidari. dad con ellos, los frutos de credibilidad de esa Iglesia a través sobre todo de los miles de mártires que ha producido. Debería ver en esa Iglesia la forma histórica de ser sacramento de salvación en pueblos crucificados. Y debería valorar también los esfuerzos por construir una lglesia para esa tarea: las comunidades eclesiales de base la inculturación, los nuevos esfuer. zos teológicos, etc.

El sinodo esta ante una importante y decisiva tarea de evaluar el concilio $y$ sus frutos. Unos recalcarán más sus exageraciones $y$ desviaciones $y$ 
propondrán una restauración involuti- de llegada que deba ser superado, y va $e$ integrista. Otros exigirán una ma. quizas anulado, sino un punto de paryor y más radical a los principios del tida para seguir caminando según su concilio. Verán en éste no un punto espíritu. 